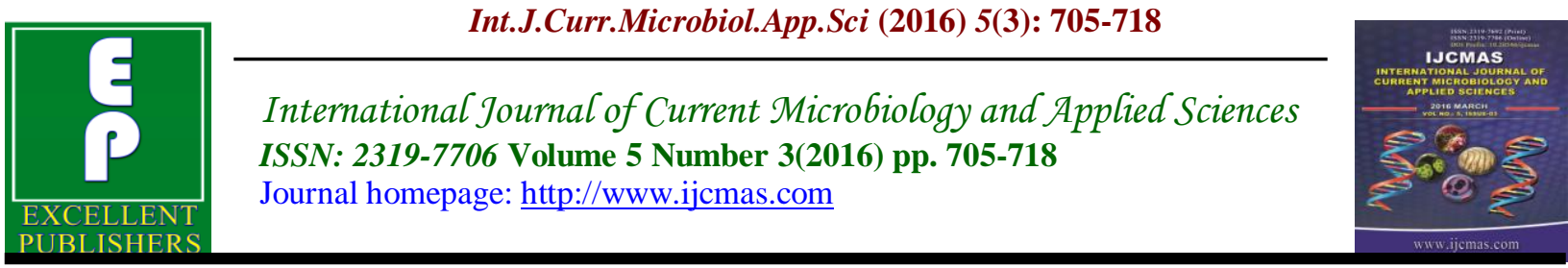

Original Research Article

http://dx.doi.org/10.20546/ijcmas.2016.503.083

\title{
Role the Employee of Some Biological Stains in Detecting Giardia lamblia among Internal Iraqi Displaced Peoples in Kirkuk Province
}

\author{
Yahya Jirjees Salman ${ }^{1}$, Abdul-Rahman Aziz Al-Taee ${ }^{2}$ and Ali Mohammed Abid ${ }^{3}$ \\ ${ }^{1}$ College of dentistry, Kirkuk University, Iraq \\ ${ }^{2}$ College of Medicine, Tikrit University, Iraq \\ ${ }^{3}$ College of Science, Tikrit University, Iraq \\ *Corresponding author
}

\begin{abstract}
A B S T R A C T
Keywords

Giardiasis, formal-ether, Calcofluor, Chromotrope

2R,

Giemsa.

Article Info

Accepted:

20 February 2016

Available Online:

10 March 2016

Giardiasis is waterborne disease which had impact on public health in anywhere of the world, particularly in communities living under low level of sanitation and poor hygienic condition. Selection of such laboratory methods with high accuracy and precise technique recently had great role in reducing the rate of intestinal parasites in general and Giardia lamblia in particular. So the current study was conducted to fulfill this purpose. Three different microscopic based laboratory techniques namely direct double wet preparation, formal-ether and fecal stained smears by 9 different biological stains were applied for detecting Giardia lamblia stages in a total of 417 stool samples of Internal Iraqi Displaced peoples(IIDPPs) in Kirkuk city. The overall rate of Intestinal parasitic infection was $19.66 \%(82)$,, which included $10.31 \%(43)$ as pure giardiasis and $9.35 \%(39)$ for other 9 intestinal parasites. They involve: Blastocyst homonis $4.17 \%$, Entamoeba histolytica 1.67 $\%$,Cryptosporidium parvum $1.43 \%$, Entamoeba coli $0.71 \%$, Cyclospora cayetanensis, $0.49 \%$, and $0.23 \%$ for each of Entamoeba hartmani, Iodomoeba butschili, Hymenolepis nana and Ancylostoma duodenale. Statistically formalinether technique show high efficacy and significance than wet preparation technique in demonstrating other intestinal parasites. Eighty two positive samples were tested as fecal smears stained by nine different biological stains were examined by microscope. High rates of giardiasis $36.58 \% .34 .14 \%, 32.92 \%$ and $25.6 \%$ were recorded by using alcoholic eosin $1 \%$, modified Gram staining+chromotrope 2R, alcoholic aceto-carmine $1 \%$ and calcofluor white stains respectively. Followed by $24.39 \%, 23.17 \%$ and $19.15 \%$ for Chromotrope 2R,trichrome stain and modified Ziehl-Neelsen stains respectively. While low rates $10.97 \%$ and $7.31 \%$ were recorded for haematoxyline-Ehrlich and $3 \%$ of giemsa stain respectively. Giardiasis was contributing high rate from intestinal parasites among IIDPs, which had high healthy impact of this group of Iraqi communities. Fecal smears staining methods show high efficacy than direct microscopy and sedimentation technique in detecting and demonstrating Giardia lamblia microscopically, specially $1 \%$ of alcoholic eosin, alcoholic aceto-carmine and modified gram staining-hot chromotrope $2 \mathrm{R}$ stains.
\end{abstract}




\section{Introduction}

Diagnosing gastrointestinal protozoa by microscopic examination is a well described laboratory technique that lends itself to decades of standardization and international adoption(Salman et al.,2001). While different institutions may adopt slightly different procedures for examining stools for ova and parasites $(\mathrm{O} \& \mathrm{P})$, the core process in North Iraq is largely conserved to: specimen fixation/collection, concentration, and microscopic evaluation. (reviewed in McHardy et al. ).While few attempts were carried out in demonstrating some intestinal parasites by staining the fecal smears with some biological stains such modified ZiehlNeelsen method(mZN),Safranine methylene blue,and giemsa stain applied on Cryptosporidium parvum in Kirkuk city by (Othman,2000)and (Salman and Mustafa,2013). Regarding Giardiasis is a disease caused by a flagellate protozoan parasite, Giardia lamblia (order Diplomonadida, family Hexamitidae) and affects people worldwide including people living in developed countries, but is more prevalent in areas with inadequate sanitary conditions(El-Safi et al., 2013). It is one of the most important non-viral infections causing diarrheal illness in humans (Meyer 1990; Dib et al. 2008).

Giardia lamblia is recognized as the most common intestinal protozoan parasite infecting humans in Iraq (Abd-Alzahra et al, 2012) particularly in Kirkuk Province (Salman and Mustafa, 2013).These diseases are often overlooked during routine parasitological or serological testing of intestinal parasites (Salman and Salih, 2013).Depending on availability of equipment, reagents, technical experience, considerations of time, and cost, there are several methods for the detection of giardiasis (Ndao 2010). Microscopic examination of stool samples, either direct or concentrated, for the recovery of $G$. lamblia both stages trophozoites and cysts(CLSI,2005).

The recent crisis and violence lead to massive population movement, and presence of over 1,500,000 internal displaced in Iraq (Xiao et al., 1999). The displacement of populations from different communities often brings people into proximity either due to increased concentrations of displaced populations and also increased density in terms of the living environment(Salman et al,2015 a). If one group is a carrier of illness, disease outbreaks reflecting endemic pathogens circulating within the community may occur (Watson et al., 2007). Because of the internally displaced persons are at high risk for emerging parasitic infections, since in most cases they have a history of poor utilization of medical care and vaccination, living conditions of low socioeconomic status and a high possibility to be carrying symptomless diseases, so it is important to carry out an assessment for diarrheal risk factors particularly intestinal parasites with an emphasis on Giardia lamblia and to avoid any health risks. Moreover we didn't find any study in Iraq concern the Giardia parasite staining, therefore this study was conduct to investigate giardiasis rate in this particular category and to study the efficacy and role of some biological stains in demonstrating of Giardia lamblia in fecal smear.

\section{Materials and Methods}

\section{Time and Location}

From 1st of September 2014 to 30th of June of 2015, cross sectional study was conducted in laboratory department of dentistry College Kirkuk University, and in Ibn-Nafies private medical laboratory. 


\section{Source of Samples}

A total of 417 stool samples were chosen from internal displaced persons living in schools, houses under construction and rented accommodations and houses in over 12 residential districts in Kirkuk city with variant economical and hygienic levels and those people are originated from different cities and villages like Anbar, Mosul,SalahEldin, Diyala, Fallujah and other areas which severely affected from conflicts and crisis in Iraq. Sample size was validated by applying the equation of sample size determination in unknown population. Patients are segregated into age groups for both males and females subjects by applying Yule method (Danielm, 1985). Also sample chooses were involve two sources: 360 stool samples for peoples living under low level of sanitations, low income and poo hygienic condition. Whereas 57 stool samples for people living in normal goo level of sanitation, high income and good level of hygiene were chosen.

\section{Stool Samples Collection}

Prior to sampling a special questionnaire was filled for each patients consisting of essential information. Disposable container with wide screw lid was given to each patient to bring stool samples. The container label contain: name, date, address and number of container. Immediately about 3-5 $\mathrm{ml}$ of Potassium chromate solution was added to each container for preservation (Salman, 2015). Stool samples were kept in ice box and transferred directly to laboratory department for processing

\section{Sample Processing and Microscopic Examination}

Which involve direct microscopy, sedimentation technique and fecal smear staining by using: hot modified Ziehl-
Neelsen(MZN), chromotrope 2R, quick hot chromotrope $2 \mathrm{R}$ modified gram staining, Fluorescent direct method, Acetocarmine,Calcofluore stain and haematoxyline Erlich.All of the stains powders and chemical were purchased from Sigma-Aldrich company by the means of Irazek company in Netherlands who send all materials to Alassala local company in Kirkuk city-Iraq. After samples arrival to laboratory, each sample was examined for detectingGiardia lamblia stages and other intestinal parasites stages using direct double wet preparation of $0.85 \%$ of $\mathrm{NaCl}$ and $1 \%$ of lugols iodine (Salman, 2015a).While formalin -ether technique was applied as follows: $10 \mathrm{ml}$ of formalin was added in a clean test tube containing approximately $1 \mathrm{gm}$ of stool sample, the tube then agitated for two minutes till to obtaining cloudy suspension. A second centrifuge tube was fixed in a plastic rack and double layer of gauze was fitted in a funnel fixed in the top of centrifuge tube; carefully the content of first tube was converted into the tube on the rack. The funnel and gauze were removed and $3 \mathrm{ml}$ of ethyl acetate or ether-ether was added quickly and the tube was plugged with rubber. The tube was converted several times then centrifuged for 3 minutes using $3000 \mathrm{rpm}$. The supernatant was discarded and few drops of malachite green $3 \%$ stain or lugols iodine 3\% was added to deposit. The tube was shacked for several times all content of the deposit were examined using $10 \mathrm{X}$ and $40 \mathrm{X}$ This procedure was done according to that described by (Salman and Mustafa,2013 and (WHO,1991).

\section{Fecal Smears Staining Method}

\section{Modified Ziehl_Neelsen (hot technique)}

The benefit of this method was that red color of strong carbol fuschin when penetrated by heating during staining process; it cannot be 
removed by washing with 5 o/o of $\mathrm{HzSO}_{4}$ so, the oocysts appears as pink to red,while other constituents of the slide will retain blue color of methylene blue counter stain; Belosevic et al., ,2004).The procedure briefly was involve the following steps: For each stool specimen two smears were prepared,Fecal smears were completely dried and fixed either by gently passing the background of the slide on benzene burner, or by flooding the smear with few drops of methanol. After drying, the slides were placed on staining rack and flood with carbol fuchsin stain, the background of the slides were gently heated with avoiding steaming and dryness of the smear. After 3 to 5 minutes, the excess amount of carbol fuchsin was discarded, washed with tape water and the smear was covered with decolorizing solution for about one minute. Gently agitated for 30 to 1 minute. The slide was rinsed with tap water to remove an excess of decolorizing solution, air dried, then after flooded with counter stain the methylene blue for two minute. An excess amount of methylene blue was discharged and the slide was rinsed with water till disappearance of blue color, left to dry, and then examined under $40 \mathrm{X}$ and $100 \mathrm{X}$ to demonstrate Giardia stages (Salman, 2015b). Chromotrope 2R stain :This staining method was developed at CDC using various components of the trichrome staining method to differentiate Microsporidia spores from background fecal elements. Reagents: which consist of two solutions, the first was Chromotrope 2R stain, which consist of Chromotrope 2R powder $6 \mathrm{gm}+0.15 \mathrm{gm}$ of fast green stain powder+ phospho-tungstic acid 0.70 gm.All of these materials was dissolved in 100 of distilled water,mixed on roller shaker for about 1 hour and kept in dark container. The second solution was acid alcohol which consists of $995.5 \mathrm{ml}$ of absolute alcohol + $4.5 \mathrm{ml}$ of glacial acetic acid kept in container and stored in cold place. Both of the reagents should be monthly prepared. Also $95 \%$ and xylene were required for distaining and clearing. The procedure briefly included the following steps: After preparing all requires reagents which described in above the following procedure was performed: Fecal smears were fixed using a small portion of absolute methanol for 1-2 minutes. Fecal smear was covered with chromotrope stain for 90 minutes. Every 10 minutes the slide was watched to avoid dryness. The smear was distained by adding acid alcohol for only 1 to 3 seconds. The smear was dipped in $95 \%$ of ethanol.The smears were exposure to $100 \%$ of absolute ethanol for long of 3 minutes in each The smears were transferred to two changes of xylene or xylene substitute for 10 minutes each. The slide was kept to dry and mounted with coverslip using mounting media(DPX). Examined using at least 100x objective oil immersion or higher. At least 50 to 100 oil immersion fields should be examined to exclude negative and to approve positivity for Giardia stages (Moura et al., 1997) Quick-Hot GramChromotrope Staining Procedure: This is an alternative stain to the chromotrope procedure that is a fast, reliable, and simple method of staining smears to demonstrate Microsporidian spores in fecal and other clinical specimens. Reagents: Gram Stain Kit and Chromotrope 2R Stain (of Chromotrope $2 \mathrm{R}$ powder $1.0 \mathrm{gm}+0.15 \mathrm{gm}$ of fast green stain powder+ phospho-tungstic acid $0.25 \mathrm{gm}$.All of these materials was dissolved in 100 of distilled water,mixed on roller shaker for about 1 hour and kept in dark container. The second solution was acid alcohol which prepared as it was described in the above).Note: In addition to the listed reagents, a method for heating reagents and maintaining a specific temperature is required. Since only the chromotrope stain needs to be warmed, a hot 
plate will suffice. The procedure briefly included the followings: Fecal smears were fixed either by gently flaming on benzene burner or by dipping in absolute methanol free acetone for about 1 minute. Gram's stain procedure has been performed except last step the safranine adding as follow as: The slides were covered with gentian violet solution and left for 30 seconds. An excess stain was removed and gently washed with water. Gram's iodine solution was added and allowed to remain on the slide for 30 seconds. Gram's iodine solution was removed by gently rinsing with decolorizer solution. The slide was hold at an angle and decolorizer solution was drop wise until it flows off the slide colorless. Extra care during this step to achieve correct staining of spores has be taken in consider. The slide was gently washed with cold water to remove excess decolorizer solution. Chromotrope $2 \mathrm{R}$ stain was applied as follows: The slide was placed in warmed $\left(50^{\circ}\right.$ to $\left.55^{\circ} \mathrm{C}\right)$ Chromotrope stain for at least 1 minute. For tissue sections, extend time 30 seconds. Rinsed in 90\% acid-alcohol for 1 to 3 seconds. An extra care during this step to achieve correct staining of spores has been given. Rinsed in $95 \%$ ethanol for 30 seconds. A second rinse twice for 30 seconds each time, in $100 \%$ ethanol (two separate containers are required for this step) were performed.The slides were completely dried' then mount with cedar wood oil immersion (Finegold and Baron ,1986) Calcofluor White Stain: This stain was consists of Calcofluor White M2R $1 \mathrm{~g} / \mathrm{l}+$ Evans blue $0.5 \mathrm{~g} / \mathrm{l}$. Procedure: A small portion of stool sample to be examined was placed onto a clean glass slide. One drop of Calcofluor white stain was added and one drop of $10 \%$ Potassium Hydroxide was placed after. A clean coverslip was covered over the specimen and left stand for 1 minute. Examined under UV light at x100 to x400 magnification (Murray et al.,1999)
and(Harrington and Hageage, 2003).Giemsa Stain: Giemsa's stain was used to demonstrate the presence of blood parasite such as malaria. Also it was used for staining the intestinal parasite( Karyaghdi, 2013). The stock of the stain was purchased from local scientific bureau in kirkuk city.Working giemsa stain was prepared as adding $10 \mathrm{ml}$ of giemsa stock stain to $90 \mathrm{ml}$ of phosphate buffer saline(PBS) pH:7.2. (WHO,1995).Procedure: For each stool sample 2 fecal smears were prepared, dried and fixed by gently heating. Methanol fixation not applied to avoid an excess of red color(because giemsa stain itself contain methanol alcohol).fecal smears were flooded with diluted Giemsa's stain and left for 10An excess of giemsa stain was discarded, the smear was rinsed with PBS and then after with D.W.Air dried and examined using 10X and 100X of microscope objective lenses. Aceto-carmine: Four grams of borax carmine was dissolved in $100 \mathrm{ml}$ of absolute ethanol alcohol, and then acid $\mathrm{pH}$ was assessed by $\mathrm{pH}$ gradient paper(Drury and Wallington,1967). Procedure: For each stool sample 2 fecal smears were prepared, dried and fixed 2-fecal smears were flooded with in aceto-carmine stain and left for 10- 15 minutes. An excess of aceto-carmine stain was discarded, the smear was rinsed with PBS and then after with D.W. Air dried and examined using 10X and 100X of microscope objective lenses. by gently heating.

\section{Results and Discussion}

From the examining of 417 stool samples using direct double wet preparations, the overall rate of the intestinal parasitic infections was $19.66 \%$ distributed in 82 stool samples. This rate involve $10.31 \%$ (43) as pure Giardia lamblia infection and $9.35 \%$ ( 39) for other intestinal parasitic infections. Statistically the differences 
between giardiasis and other intestinal parasitic infections in regard of direct microscopy was not significant, $\mathrm{P}>0.05$. Nine species of other intestinal parasites were recorded in current study beside Giardia lamblia. The rates were: $4.176 \%$ for Blastocyst homonis followed by $1.678 \%$, $1.438 \% .0 .719 \%$, and $0.479 \%$ for Entamoeba. histolytica Cryptosporidium parvum, Entamoeba coli, Cyclospora cayetanensis. While low rate $0.239 \%$ was recorded for each of Entamoeba hartmani, Iodomoeba butschili, Hymenolepis nana and Ancylostoma duodenale, $\mathrm{P}<0.05$; Table (1).

To get accurate and more precise rate of giardiasis in addition to assess the efficacy of suitable laboratory methods in detecting Giardia lamblia and other intestinal parasites, the all 417 stool samples were examined using direct double wet preparations in parallel with formalin-ether sedimentation technique. The results were obvious in table-2; which exert $5.51 \%$ of Giadia lamblia stages using ether formalin compare to $4.79 \%$ using double preparations, $\mathrm{P}>0.05$. While other intestinal parasitic rate $6.23 \%$ by using etherformalin technique was higher than $3.12 \%$ using double preparations, $\mathrm{P}<0.05$. Whereas collectively Giadia lamblia and other intestinal parasites statistically show significant differences between to laboratory methods; through which ether-formalin technique contribute $11.75 \%$ from total of $19.66 \%$ for detecting parasitic stages in stool samples compare to $7.91 \%$ by using double wet preparation method, $\mathrm{P}<0.05$.

Figure (1) was showing the effects of nine different biological employed stains in demonstrating Giardia lamblia microscopically in fecal smears. From all positive specimens (82) $19.66 \%$ fecal smears stained were stained each one separately by 9 stains, the results in the following figure were reveal fluctuated results as the high rates of giardiasis were recorded $36.58 \%, 34.14 \%, 32.92 \%$ with alcoholic eosin, modified gran stain-hot chromotrpe2R and Aceto-carmine respectively. Followed by Calcofluor white stain, chromotrope $2 \mathrm{R}$, trichrome stain and modified Ziehl-Neelsen stain, the rates were : $25.6 \%, 24.39 \%, 23.17 \%$ and $19.15 \%$ respectively. While lower rates $10.97 \%$ and $7.31 \%$ were recorded with haematoxyline Ehrlich and giemsa stains, Statistically the assessment of the efficacies of stains was significant among 9 stains. Also the efficacies of alcoholic eosin, modified gran stain-hot chromotrpe2R, Aceto-carmine respectively, Calcofluor white stain, chromotrope 2R, trichrome stain and modified Ziehl-Neelsen stain statistically were significant and superior to direct double wet preparations and formal ether methods.

Figure(2) was exerting Giardia lambliia trophozoites stained with calcofluor white,the left picture was showing lemon shaped of two cystic stages while the right picture was showing ellipsoidal like pear shape trophozoites. Both stages were retaining whitish color of fluorescent part of calcofluor stain using ultra-violet filter of fluorescent microscope. Some small oval whitish elements also were seen in microscopic field representing fungal yeasts belong to normal fungal biota such as Candia species (monilia).

Figure (3) was consist of two illustrated photos representing Giardia lamblia stages, the left picture was showing cystic stage as shrieked pink to light orange.Internal constituents such as axostyle, axoneme, median bodies and 4 nucleus were compacted as a more dense mass in one corner of the cyst. While right picture was stained fecal smear with chromotrope $2 \mathrm{R}$ 
stain demonstrating fixed pear shaped light brownish to grey color of Giardia trophozoite, both nucleus were dense in brown color surrounded with clear zones (suckers) around of each nucleus. Moreover axostyle and median bodies were not clear.

The effects of alcoholic eosin 1\% stain in the left picture of the figure (4) was obvious in demonstrating Giardia lamblia trophozoites as purple bright color against faint pinks background containing other stool samples compartments.

Meanwhile right picture was exerting the Giardia stages both throphozoite(left arrow) and cystic stage(right arrow)both stages were weakly stained with $3 \%$ of giemsa stain as they seen very light bluish to grey. Additionally the internal contents of both Giardia stages were not obvious using microscopic examination.
Although Giardia lamblia trophozoite was considered as none acid fast microorganisms but, in current study $19.15 \%$ from all positive slides for parasites were stained with modified Zhiel-Neelsen (hot technique).The stained stages were weakly stained reverse to bluish or greenish background according to used counter stains (methylene blue or $3 \%$ of malachite green).The internal organelles and external flagella were not recognized microscopically. Figure (5). On the other hand modified gram staining -hot chromotrope $2 \mathrm{R}$ procedure was high rate $34.14 \%$ of Giardia parasite stages. The trophozoites were stained as pale red to pink, while internal contents were retain dark red in color containing dark brown to black round mass most like representing the two nucleuses in the center of sucking discs, the same figure.

Table.1 Distribution of Giardia lamblia and Other Intestinal Parasites by Using Direct Microscopy

\begin{tabular}{|l|l|l|l|l|}
\hline \multirow{2}{*}{ Parasites types } & \multicolumn{2}{l|}{ Positive } & \multicolumn{2}{l|}{ Negative } \\
\cline { 2 - 5 } & NO & $\%$ & No & $\%$ \\
\hline Giardia lamblia & $\mathbf{4 3}$ & $\mathbf{1 0 . 3 1}$ & $\mathbf{3 4 7}$ & $\mathbf{8 9 . 6 1}$ \\
\hline Other intestinal parasites & $\mathbf{3 9}$ & $\mathbf{9 . 3 5}$ & $\mathbf{3 7 8}$ & $\mathbf{9 0 . 6 5}$ \\
\hline Total & $\mathbf{8 2}$ & $\mathbf{1 9 . 6 6} *$ & $\mathbf{3 3 5}$ & $\mathbf{8 0 . 4 4}$ \\
\hline
\end{tabular}

\begin{tabular}{|c|c|c|c|c|}
\hline Other Intestinal Parasites & \multicolumn{2}{|c|}{ Positive } & \multicolumn{2}{|c|}{ Negative } \\
\hline Type of parasites & NO & $\%$ & NO & $\%$ \\
\hline Blastocyst homonis & 17 & $4.176 *$ & 400 & 95.824 \\
\hline Entamoeba.histolytica & 7 & 1.678 & 410 & 98.322 \\
\hline Cryptosporidium parvum & 6 & 1.438 & 411 & 98.562 \\
\hline Entamoeba.coli & 3 & 0.719 & 414 & 99.281 \\
\hline Cyclospora cayetanensis & 2 & 0.479 & 415 & 99.521 \\
\hline Entamoeba hartmani & 1 & 0.239 & 416 & 99.761 \\
\hline Iodomoeba butschili & 1 & 0.239 & 416 & 99.761 \\
\hline Hymenolepis.nana & 1 & 0.239 & 416 & 99.761 \\
\hline Ancylostoma duodenale & 1 & 0.239 & 416 & 99.761 \\
\hline Total & 39 & 9.352 & 378 & 90.648 \\
\hline All Total & 82 & 19.66 & 355 & 80.44 \\
\hline
\end{tabular}

$* \mathbf{P}<0.05$ 
Table. 2 Comparison between the Employ of Direct Double Preparations Technique and EtherFormalin Sedimentation Technique in Detecting Giardia lamblia in Stool Samples

\begin{tabular}{|c|c|c|c|c|c|c|c|c|c|c|c|c|}
\hline \multirow[t]{3}{*}{ Lab methods } & \multicolumn{4}{|c|}{ Giardia lamblia } & \multicolumn{4}{|c|}{$\begin{array}{c}\text { Other intestinal } \\
\text { parasites }\end{array}$} & \multicolumn{4}{|c|}{ Total } \\
\hline & \multicolumn{2}{|c|}{ Positive } & \multicolumn{2}{|c|}{ Negative } & \multicolumn{2}{|c|}{ Positive } & \multicolumn{2}{|c|}{ Negative } & \multicolumn{2}{|c|}{ Positive } & \multicolumn{2}{|c|}{ Negative } \\
\hline & No & $\%$ & No & $\%$ & No & $\%$ & No & $\%$ & No & $\%$ & No & $\%$ \\
\hline $\begin{array}{l}\text { Double wet } \\
\text { preparations }\end{array}$ & 20 & 4.79 & 397 & 95.21 & 13 & 3.12 & $\begin{array}{c}40 \\
4\end{array}$ & 96.88 & 33 & 7.91 & 384 & 92.21 \\
\hline $\begin{array}{l}\text { Formalin-ether } \\
\text { technique }\end{array}$ & 23 & $\begin{array}{c}5.51 \\
\mathrm{~A}\end{array}$ & 394 & 94.49 & 26 & $\begin{array}{c}6.23 \\
\text { B }\end{array}$ & $\begin{array}{c}39 \\
1\end{array}$ & 93.27 & 49 & $\begin{array}{c}11.75 \\
\mathrm{C}\end{array}$ & 368 & 88.25 \\
\hline Total & 43 & 10.31 & 335 & 89.68 & 39 & 9.35 & $\begin{array}{c}37 \\
8\end{array}$ & 90.65 & 82 & 19.66 & 335 & 80.44 \\
\hline
\end{tabular}

$\mathrm{A}=\mathrm{P}>\mathbf{0 . 0 5} \quad \mathrm{B}$ and $\mathrm{C}=\mathrm{P}<0.05$

Figure.1 Frequency of Giardia lamblia According to Type of Fecal Smear Staining Procedures

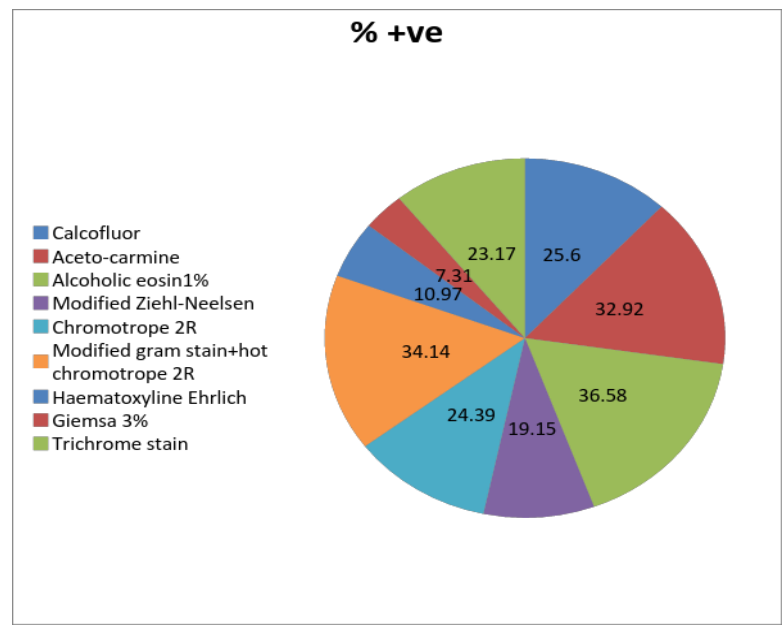

Figure.2 Calcofluor White Stain Demonstrating Ellipsoidal to Pear Shaped Giardia lamblia Trophozoites using Fluorescent Microscope- Ultraviolet Wave Length
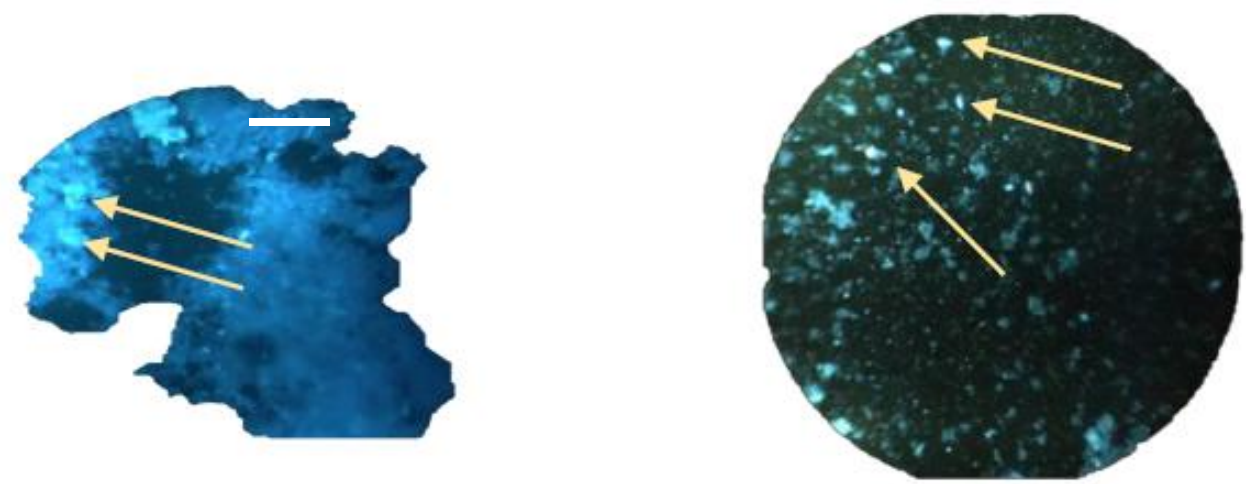
Figure.3 Right Showing Giardia lamblia using Aceto-carmine While the Left is Showing Staining with Chromotrope 2R
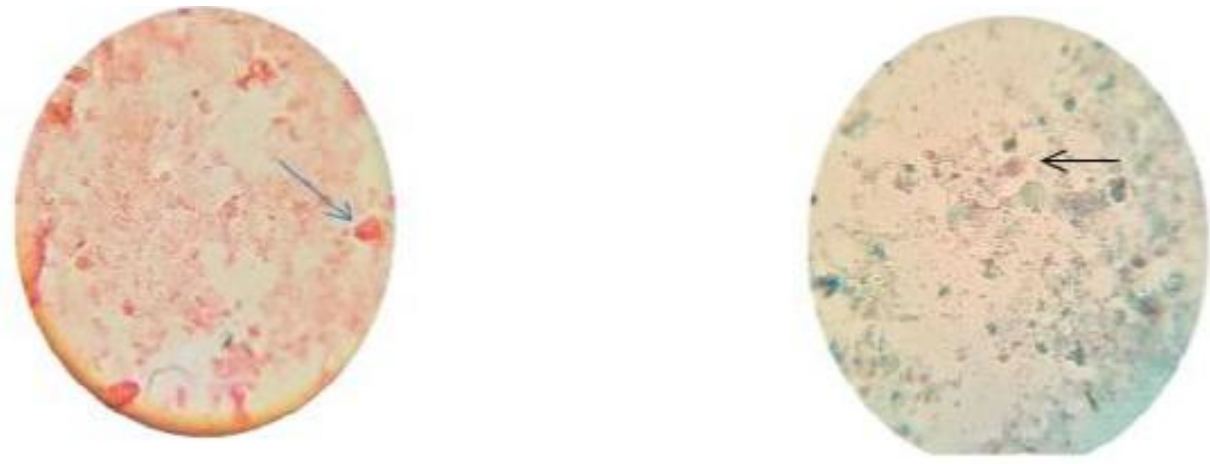

Figure.4 Right Picture Presenting Giardia lamblia Trophozoites by $1 \%$ of Alcoholic Eosin Stain. The Left Showing the Parasites Weakly Staining by $3 \%$ of Giemsa Stain, $20 \mathrm{X}$
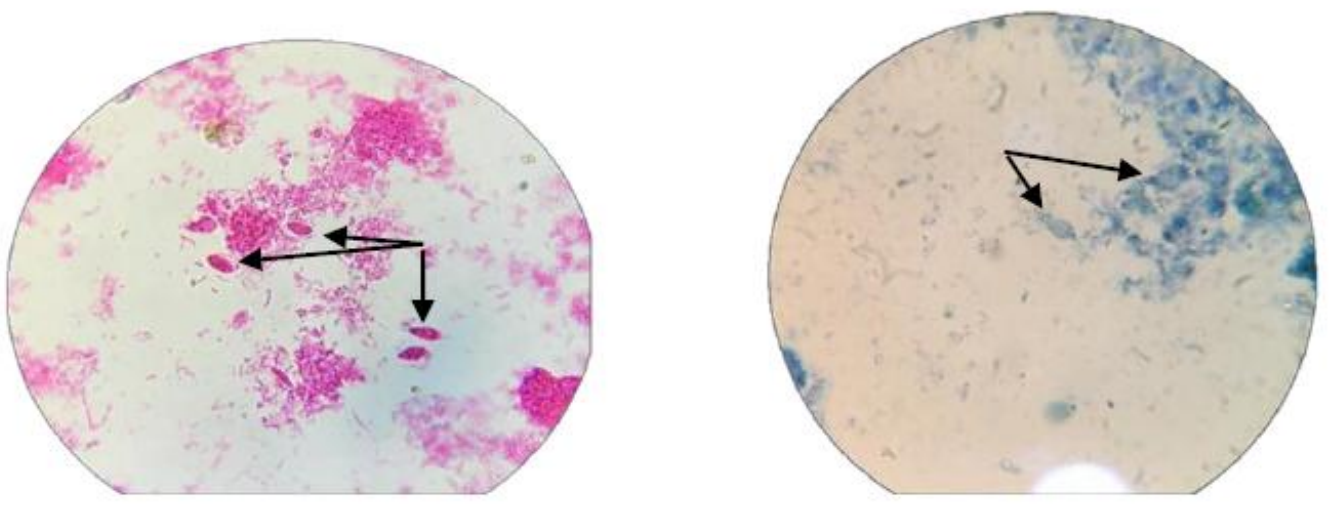

Figure.5 Right Picture is Showing Unstained Trophozoite of Giardia lamblia by Modified Z.N.Stain While the Left is Presenting Well Stained Trophozoites with Modified Gram Staining -Hot Chromotrope 2R
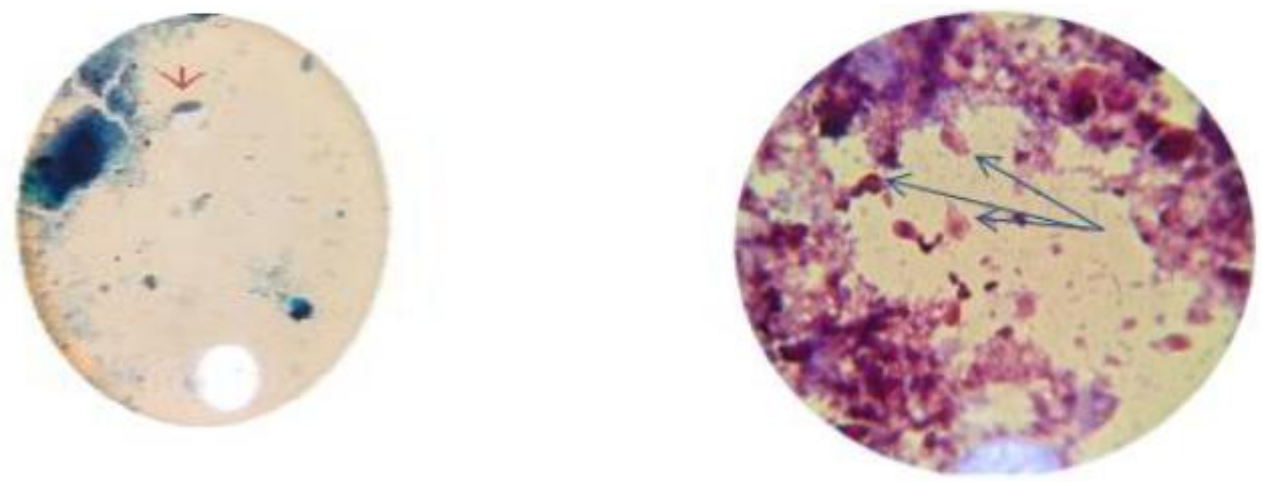
Figure.6 Right Picture is Presenting Haematoxyline Ehrlich Staining.Left is Trichrome Staining of the Giardia Parasite $20 \mathrm{X}$

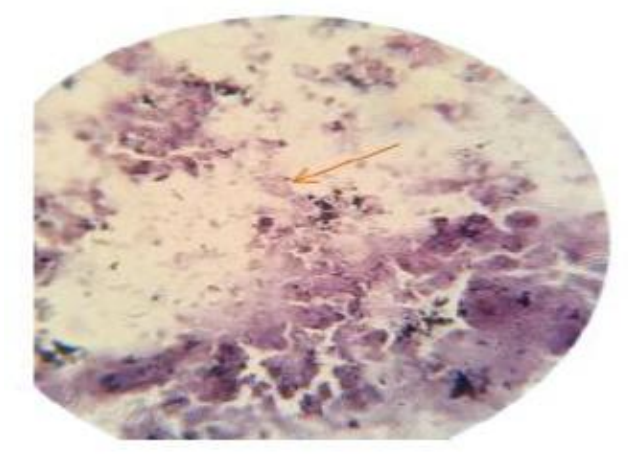

Regarding fecal smears staining by trichrome stain, this study was reveal 23.17 $\%$ of Giardia positivity microscopically. The right picture in figure (6) was presenting the well staining the parasite specially the internal constituents such as median bodies and axostyle in addition to well visualizing the nucleuses and sucking discs. The trophozoites had pear shape rounded anteriorly and highly tapered posteriorly. Other stool samples depress were retain light red color such as yeasts controversy to some sloughed tissue that retain dark red color. The left picture in the same figure was exerting Giardia stages staining by Ehrlich-haematoxyline which show $10.97 \%$ positivity with weakly staining the internal compartments of the parasite.Giardia stages were stained pale reddish with slightly deep color of the nucleases resides in sucker discs.

The rate of Giardia lamblia $10.31 \%$ among IDPs in current study was not agree with the following ratios recorded in Iraq: 25.33 $\%, 30.39 \%, 35.89 \%, 37.5 \%, 44.59 \%$ and $45.9 \%$ for giardiasis in Kirkuk Province, Kirkuk city, Erbil, Al-Tammen, Basrah and Tikrit Provinces by (Kadir et al., 2000); (Kader and Salman,1999), (Kadir et al., 1987), (Jar-Allah, 2012) and (Al-Somadayi, 2012) respectively. Also the rate of

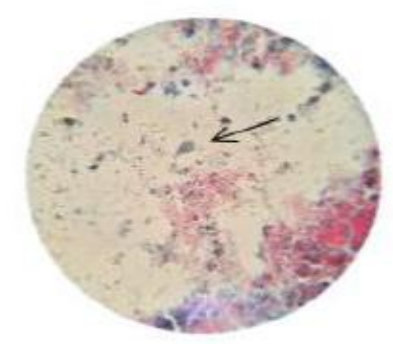

giardiasis $10.31 \%$ in current study was lower than $18 \%, 25.33 \%, 62.2 \%, 67.6 \%$ and $89.5 \%$ recorded in Iran, Yemen, Egypt, Colombia and Chanaby (Taherkhan et al., 2009), (Al-Yousefi et al.,2013), (Yassin et al., 2000), (Jorge et al.,2009) and( Nkrumah and Nguash,2011) respectively. This finding reflects the degree of contamination with parasitic phases among this group of peoples in Kirkuk community. The reason to that most often might be related to nature of water consumption and water quality and water supply. It has been known, that a big construction for improving of roads and infra-structure in Kirkuk province from 2008 to 2014was carried on. This action lead to breakdown of water pipes underground, because all of these pipes are very old, this lead to continue of water supply interruption in this Province. The second reason to this high rate might be attributed to uncontrolled migration and inhabitation of IDPs to old buildings, in complete building, old schools. Moreover 4 to 5 families live in one house (highly crowded).All of these factors have had role in increasing the rate of intestinal parasites particularly giardiasis in current study. This finding was not agreed with those recorded in the same Province by (Salman et al., 2015), whom they record $7.05 \%$ of giardiasis among IDPs in the same governorate. It is not clear how much 
these differences may be explained by differences in study design, geographical location, population group, and sensitivity of laboratory methods, stage of disease or type of laboratory tests.

Regarding no differences between direct double wet preparation and formal ether concentration technique in detecting giardiasis as $4.79 \%$ and $5.51 \%$ for both techniques respectively that show no significant differences between them. As a scientific role stool examination by concentration method has had high efficacy than double preparation microscopically (McHardy, 2014). Low variance might be attributed to usage of sedimentation (Formal-ether technique) instead of flotation technique in current study. Moreover due to light weight of Giardia that might be floated on the top of the used solution(etherformalin) which not examined properly because the examination mostly depended on deposit examination comprehensively. On the other hand significant differences between 2 employed methods in detecting other intestinal parasites,as $6.23 \%$ detecting by formal ether compare to $3.12 \%$ by double preparations. This finding was agree with that used by Salman and Salih,2013 and Salman,2014,while not agree with that applied by Salman, et al,.2015) in the same province.

Considering fecal smears staining by 9 different biological stains, Eosin stain exerting high rate of positivity for giardiasis in current study can be interpreted by usage of alcoholic eosin instead of aqueous, the former may had strong role in penetrating the cell wall and cytoplasm of Giardia parasite than the later eosin. Eosin is a fluorescent acidic / negative compound that binds to and forms salts with basic, or eosinophilic, compounds containing positive charges (such as proteins that are basic / positive due to the presence of amino acid residues such as arginine and lysine) and stains them dark red or pink as a result of the actions of bromine on fluorescein. In addition to staining proteins in the cytoplasm, it can be used to stain collagen and muscle fibers for examination under the microscope(Weller, et al., 1988). The high rate of positivity might be due to high contents of proteins in the cell wall that will show high affinity to eosin stain particularly the microtubules in flagellum of Giardia parasite that anchored it to kinetoplast beneath the wall in posterior region of the trophozoite that will extend to link with flagella within a shaft in the cell wall (Hernandez, et al., 2007).

The second stain was Gram stain hot modified chromotrope 2R that show 34.14 $\%$ of positivity for giardiasis, this procedure was applied after failure of using chromotrope $2 \mathrm{R}$ staining of the fecal smears and using Gram staining+ chromotrope $2 \mathrm{R}$ for 60 minutes of staining. The affinity of Giardia cell wall to Gram staining was high as it was consider as Gram negative parasite (Brown,1978), but replacing of chromotrope $2 \mathrm{R}$ instead of safranin as counter stain for 90 minutes evoke obtaining high rate of the mentioned high rate of giardiasis.

Aceto-carmine is acidic stain mostly used for staining nematoda parasites. Its affinity for penetrating the double muscular layers (longitudinal and circular) of nematoda wall might be due to well dissolving of carmine borax with used alcohol during the preparation of the stain( Salman,1987). This feature and high content of proteins in the cell wall of Giardia parasite may be applied for explaining the high rate of $32.92 \%$ positivity of giardiasis with the use of acetocarmine. 
Calcofluor-white is a special fluorescent stain that binds strongly to structures containing cellulose and chitin in the endospore layer of the spore wall of Microsporidia,(García-Rodriguez et.al., 2000).In the current study $26.5 \%$ of fecal smears positivity by using calcofluor was vital for diagnosing Giardia stages specially trophozoites in spite of some difficult may facing new laboratory technicians such as other stool compartments may retain white color of calcofluor as the trophozoites will do(Fritzand Triemer, 1985). On the other hand this stain is somewhat expensive and requires the aid of fluorescent microscope for demonstrating the Giardia parasite. The reason of Giardia trophozoites retaining calcofluor than the cysts might be due to that the trophozoites has had thin layer that will permit good penetration of this stain to the cytoplasm which contain more food vacuoles containing cellulose in the trophozoites compare to low number of chitin and cellulose in the Giardia cysts wall.

Chromotrope 2R stain method was developed at CDC using various components of the trichrome staining method to differentiate Microsporidia spores from background fecal elements. The rate of positivity $24.39 \%$ of fecal smears in current study was high when compared to $5.7 \%$ recorded by AbduAllah,2016), who recorded the rate when she stained fecal smears for cyclosporiasis in Kirkuk city-Iraq. Variance in the rates might be due to size of sampling, rigid structure of the oocysts of Cyclospora than the stages of Giardia parasites. Furthermore the components of chromotrope $2 \mathrm{R}$ stain that consisting of more than one stains and chemicals in addition to glacial acetic acid and ethanol alcohol my increase the synergistic of chromotrope $2 \mathrm{R}$ in penetrating of Giardia cell wall that increase the positivity of this method in Giardia than Cyclospora.
Low positivity rate $19.15 \%$ of Giadiasis by using modified ziehl-Neelsen most like due to low amount of waxy materials in the cystic wall of Giardia parasite compare to that fount in the oocysts walls of Cryptosporidium parvum ( Salman,2014). Moreover it might be due the effect of an excess of heating or longer time of decolorizing by $5 \%$ of $\mathrm{H}_{2} \mathrm{SO}_{4}$ or due to other technical errors.

Regarding hematoxylin-Ehrlich stain low impact on Giardia lamblia parasite staining might be due to using prepared stain as purchased from local bureau in Kirkuk city that contain change in structure results in the conversion of the relatively colorless hematoxylin to the reddish/brown hematein. In addition, the oxidation to hematein is necessary in order to bind metal ions such as aluminum(Godwin,2011)(Puthcler et al.,1986)..Other explanation for weakly staining by this stain also might be due low amount of haematin in the cell wall of Giardia parasite.

Considering $3 \%$ stain employee which show $7.31 \%$ of fecal smear positivity, this may reflect low affinity of Giardia parasite cell wall to this percent of giemsa stain. Increasing the giemsa stain concentration may improve the efficacy of this stain for demonstrating Giardia parasite stages as this percentage of giemsa stain is the recommended percentage for staining malaria parasite stages (Barcia,2007).

In conclusion, Giardiasis was contributing high rate from intestinal parasites among IIDPs, which had high healthy impact of this group of Iraqi communities. Fecal smears staining methods show high efficacy than direct microscopy and sedimentation technique in detecting and demonstrating Giardia lamblia microscopically, specially $1 \%$ of alcoholic eosin, alcoholic aceto- 
carmine and modified gram staining-hot chromotrope 2R stains.

\section{References}

AbdulAllah,T.J.(2016). Effects of some laboratory stains for demonstrating Cyclospora cayetanensis in Kirkuk Province.M Sc thesis.Coll Sci.Kirkuk Univ.

Barcia, J.J.(2007) The Giemsa stain: its history and applications. Int $\mathbf{J}$ Surg Path;15(3):292-296.

Belosevic, M.; Yoshinobu, I.; Masato, K.; Kenji K.; Shiba-Kumar, R., Kaoru, T., \& Shoji, U.. "Comparison of three microscopic techniques for diagnosis of Cyclospora cayetanensis". FEMS Microbiology Letters, 2004; 238 : 263-266.

Brown, G. G. (1978). An Introduction to Histotechnology. Appleton-CenturyCrofts, New York.

Drury, R.A.B. and Wallington, E.A.(1967). Cartetons histological techniques, $4^{\text {th }}$ edition.Oxford Univ Press.New York:363370.

El-safi,S.H.;Al-Magati，Th.N.; Hussien, M.I.; Adam,A.M.;Abu-Hassan, M.M.and AlZahrani,E.M. (2013). Comparison of microscopy, rapid immunoassay, and molecular techniques for the detection of Giardia lamblia and Cryptosporidium parvum. Parasitol Res;112:1641-1646.

Finegold, S.M. Baron,E.J. Bailey and Scott's Diagnostic Microbiology 7th ed. C.V. Mosby St. Louis (1986).

Fritz, L. and Triemer, R. (1985). A rapid simple technique utilizing calcofluor white M2R for the visualization of dinoflagellate thecal plates. Journal of Phycology, 21: 662-66.

Garcia LS. 5th ed. Washington, DC: ASM Press; 2007. Diagnostic Medical ParasitologyFAQs; pp. 4-11.

Garcia, L. S., and H. D. Isenberg. 2010. Clinical microbiology procedures handbook, 3rd ed. ASM 398 Press, Washington, DC.

García-Rodriguez L. J., Durán A, and Roncero C. 2000 Calcofluor Antifungal Action Depends on Chitin and a Functional High-
Osmolarity Glycerol Response (HOG) Pathway: Evidence for a Physiological Role of the Saccharomyces cerevisiae HOG Pathway under Noninducing Conditions Journal of Bacteriology 182(9):2428-2437.

Godwin Avwioro (2011). Histochemical Uses Of Haematoxylin - A Review. JPCS 1:2434.

Harrington, B.J. Hageage,G.J. Calcofluor white: a review of its uses and applications in clinical mycology and parasitology, Lab Med. 2003; 34, 361 -7.

Henriksen, S. and Pohlenz, J. Staining of Cryptosporidium by a modified Ziehl Neelsen technique. ActaYeter. Scand, $1981 ; 22: 594-596$.

Hernandez Y, Castillo C, Roychowdhury S, Hehl A, Aley SB, et al. (2007) Clathrindependent pathways and the cytoskeleton network are involved in ceramide endocytosis by a parasitic protozoan, Giardia lamblia. Int J Parasitol 37: 21-32.

Karyaghdi, T.K. 2013. Study the efficacy of some laboratory methods in diagnosis of intestinal parasite among infected peoples in Kirkuk city-Iraq. M.Sc. thesis, Coll. Sci. Kirkuk Univ.

McHardy, I. H., M. Wu, R. Shimizu-Cohen, M. R. Couturier, and R. M. Humphries. (2014). Detection of intestinal protozoa in the clinical laboratory. J Clin Microbiol 52:712-20.

Meyer EA (1990) Human parasitic diseases: giardiasis. In: Meyer EA (ed) Taxonomy and nomenclature. Elsevier, Amsterdam, pp 51-60.

Moura H, Schwartz D.A, Bornay - Llinares F, et al. A new and Improved "Quick-Hot Gram-Chromotrope" Technique That Differentially Stains Microsporidian Spores in Clinical Samples, Including Paraffin-Embedded Tissue Sections. Arch Pathol Lab Med. 1997; 121: 888-893.

Murray, P.R. Baron, E. Pfaller, M. Tenover,F. Yolken, Manual of clinical microbiology, 7th ed. Washington, ASM, 1999.

Ndao,M.(2010) Diagnosis of parasitic diseases: old and new approaches. Inter-disc Perspect on Infect Dis 106(5):1127-1134. 
Nkrumah, B. and Nguah, S. (2011). Giardia lamblia: a major parasitic cause of childhood diarrhoea in patients attending a district hospital in Ghana. Parasite and Vector; (4): 163-167.

Othman, N.F. 2000. Comparison between different laboratory methods in diagnosis of Cryptosporidium parvum.High Diploma Lab Invest. thesis Coll Med Tikrit University.

Puchtler, H., Meloan, S.N. \& Waldrop, F.S. 1986. Application of current chemical concepts to metal-haematein and brazilein stains. Histochemistry 85: 353364.

Salman, Y.; Al-Alousi, T. and Hamad, S. (2001).Prevalence of intestinal parasites among people in Kirkuk city.AlmustansiriyaJ.Sci; 1: 12-20.

Salman, Y.J. (2014). Efficacy of some laboratory methods in detecting Giardia lamblia and Cryptosporidium parvum in stool samples. Kirkuk Univ.J. Sci. Stud., 9(1): 717.

Salman, Y.J. (2015a). Detection of Blastocystis hominis among peoples in Kirkuk Province using ELISA and direct microscopy.Int. J. Curr. Microbiol.App. Sci., 4(10): 686695.

Salman, Y.J.;Kadir, M.A and Abdul-Allah,, T.J. (2015b). Prevalence of Cyclospora cayetanensis and other intestinal parasites in soil samples collected from Kirkuk province. Int. J. Curr. Res. Aca. Rev., 3(10): 239250.

Salman,Y.J. and Ali,L.S.(2013).detection of some microbial infection among children aging below 2 years in Kirkuk city. J Kirkuk Med Coll;1(1):53-60.

Salman,Y.J.(1987).Survey of intestinal parasites of cats in kirkukand Baghdad cities with study of some biological aspects of Toxocara cati in-vitro.MSc thesis.Coll Sci Baghdad Univ.

Salman,Y.J.and Mustafa, M.I(2013). Evaluation of the employment of four laboratory diagnostic methods of detecting Gairdia lamblia among Children in Kirkuk city. JKirkuk Med Coll;1(2):52-60.

Watson, J., Gayer, M. et al. (2007).Epidemics after natural disasters. Emerg. Infect.Dis., 13(1): 15.

Weller PF, Ackerman SJ, Smith JA(1988). Eosinophil granule cationic proteins: major basic protein is distinct from the smaller subunit of eosinophil peroxidase. $J$ Leukocyte Biol;43(1):1-4.

World Health Organization(1991) Basic laboratory methods in medical parasitology. W.H.O Geneva :16-17.

World Health Organization(1995) Production of basic diagnostic laboratory reagents .W.H.O Geneva :167-170

World Health Organization(2003)Manual to medical laboratory investigations. WHO Geneva.

Xiao, L., Escalante, L., Yang, C. (1999). Phylogenetic analysis of Cryptosporidium parasites based on the small sub-unit rRNA. Gene locus. Appl. Environ. Microbial.,65: 1578-1583.

\section{How to cite this article:}

Yahya Jirjees Salman, Abdul-Rahman Aziz Al-Taee and Ali Mohammed Abid. 2016. Role the Employee of Some Biological Stains in Detecting Giardia lamblia among Internal Iraqi Displaced Peoples in Kirkuk Province. Int.J.Curr.Microbiol.App.Sci. 5(3): 705-718. doi: http://dx.doi.org/10.20546/ijcmas.2016.503.083 